Ecology, 101(3), 2020, e02934

(C) 2019 by the Ecological Society of America

\section{A rotiferan version of the punishment of Sisyphus?}

\author{
M. E. Perga id ${ }^{1,4}$ M. Syarki, ${ }^{2}$ N. Kalinkina ${ }^{2}$ And \\ D. BOUFFARD iD 3
}

Manuscript received 16 July 2019; revised 27 September 2019; accepted 18 October 2019. Corresponding Editor: John Pastor.

${ }^{1}$ Faculty of Geosciences and Environment, Institute of Earth Surface Dynamics, University of Lausanne, Lausanne, Switzerland.

${ }^{2}$ Northern Water Problems Institute of the Karelian Research Centre of the Russian Academy of Sciences, Petrozavosk, Russia.

${ }^{3}$ EAWAG, Kastanienbaum, Switzerland.

${ }^{4}$ E-mail: marie-elodie.perga@unil.ch

Citation: Perga, M. E., M. Syarki, N. Kalinkina, and D. Bouffard. 2020. A rotiferan version of the punishment of Sisyphus? Ecology 101(3):e02934. 10.1002/ecy.2934

In March 2017, we joined a multidisciplinary expedition on Lake Onego, in the Russian Karelia, with the primary goal to investigate zooplankton strategies to survive deep winter under ice. We intended to focus on the large zooplankters, that is, crustaceans of tenths to a few millimeters of body length, through sampling by horizontal and vertical trawls using nets of relatively large mesh size. Delays in the delivery of sampling gear compelled us to opt, at the last minute, for a much-smaller mesh size net for the horizontal trawls underneath ice. This providential net preferentially captured microzooplankton (tens to hundreds of micrometers in body length). Under the ice, zooplankton samples consisted of as much as $95 \%$ rotifers, that is, the small "wheel animalcules" of zooplankton (Fig. 1). Rotifer abundance just underneath the ice varied by more than one order of magnitude between day and night, following an unexpected rhythmicity that looked too pronounced to be random, despite the short study time (Fig. 2).

Circadian changes in the surface abundance of zooplankton are not surprising per se. Many marine and freshwater zooplankters swim upward at sunset and downward at dawn (Ringelberg 1999, Pearre 2003), with vertical amplitudes ranging from a handful to a hundred meters, a phenomenon called diel vertical migration (DVM). DVM is considered as "the largest synchronized movement of biomass on Earth" (Hays 2003) and is often attributed to an evolutionary strategy of avoiding visual predators (Pearre 2003). The processes underlying DVM have been extensively investigated on crustaceans, the freshwater Daphnia being the emblematic lab rat (Ringelberg 1999, Pearre 2003). Phototaxis, that is, light-oriented swimming direction, is central to DVM. In a nutshell, Daphnia swims towards light at low light levels and swims away from light once a certain threshold of light intensity is surpassed (Ringelberg 1999). Thereby, the relative change in light intensity, defining sunset and sunrise, is the proximal stimulus for DVM, and other environmental cues (food, oxygen concentrations, water transparency, predator presence) modulate its amplitude (Lampert et al. 2003, Ringelberg 1999). Using field-based ecological models to apply the knowledge gained at the laboratory scale on Daphnia now allows us to reproduce ocean- and lacustrine-scale patterns of DVM for many crustaceans (Ringelberg 1999).

Rotifers' DVM is much less understood. When diel vertical movements have been reported for rotifers, their timing was much more anarchic than for crustaceans, and also less obviously synchronized to changes in daylight. Diel vertical movements of rotifers have been qualified as normal (i.e., as for Daphnia), reverse, abnormal, and erratic DVM, a definition under which some rotifer species would even switch from one regime of DVM to the other in a single lake over seasons (George and Fernando 1970, Stewart and George 1987, Karabin and Ejsmont-Karabin 2005). In our case study, the abundance of rotifers was minimal immediately beneath the ice during daytime, then increased from sunset through the nighttime (Fig. 2). Yet, they began descending $3 \mathrm{~h}$ after sunrise, which seems a significantly large time lag compared to a typically normal DVM. In zooplankton, swimming capacity roughly scales to body size: rotifers' swimming speeds (a few hundreds of micrometers per second) are one order of magnitude lower than for crustaceans (millimeters per second; Obertegger et al. 2018). Because our observations were performed only at the 50$\mathrm{cm}$ depth immediately underneath ice, we missed the full vertical movement of rotifers. This means that, although we could see great temporal variation in abundance, we could not unambiguously attribute this to DVM or another mechanism. We therefore simulated how surface abundance of rotifers would change if rotifers were performing a normal DVM, using a simple model adapted for rotifers'swimming capacities (Appendix S1: Section $\mathrm{S} 1$ ).

Over the $43 \mathrm{~h}$ of simulation, changes in the under-ice abundance were considered as only driven by the vertical movements of rotifers, with, as for Daphnia, an upward swimming from sunset and a downward swimming from sunrise. The vertical migration was bounded upward by the ice sheet and downward by a "refuge layer" during 


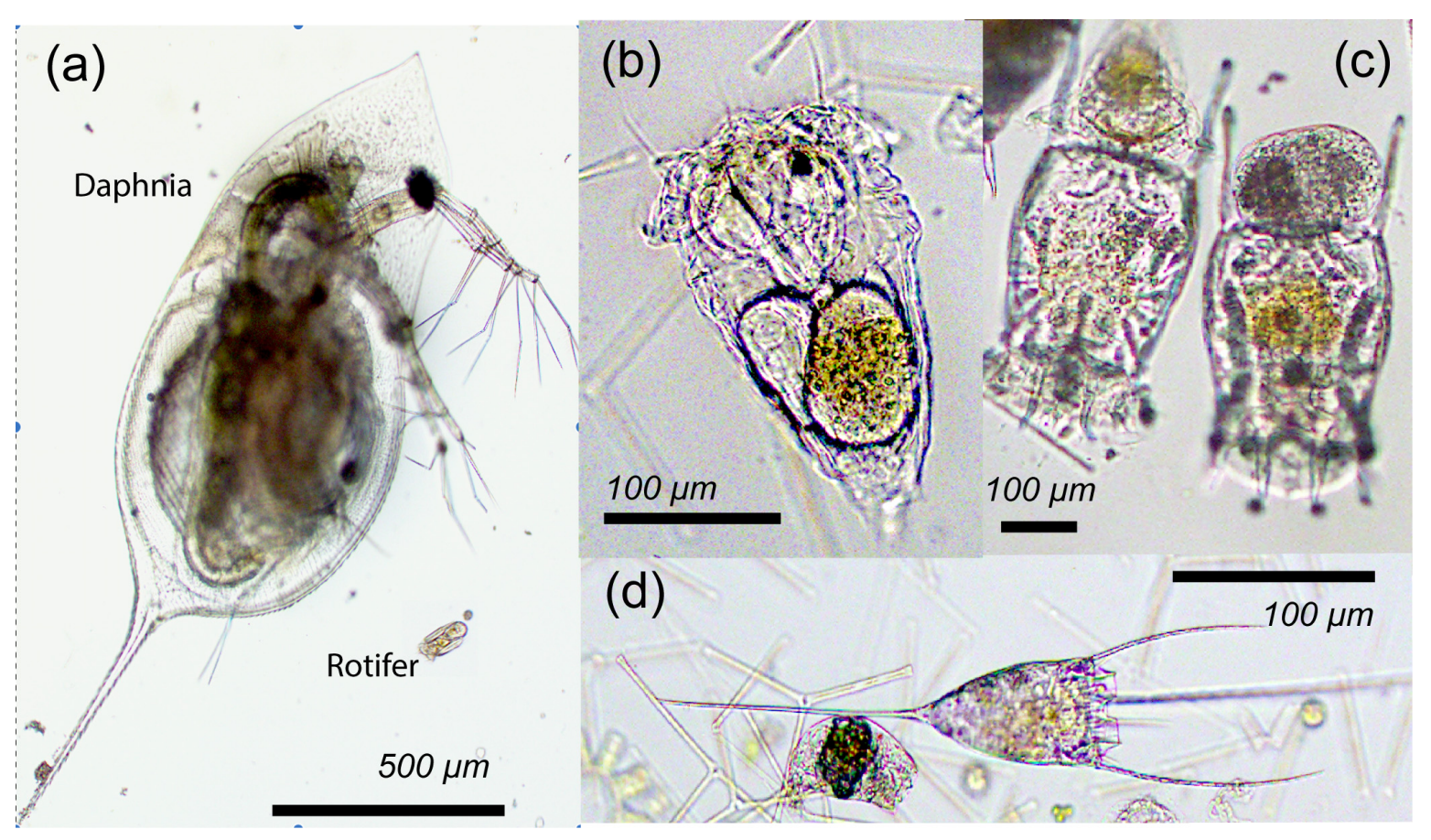

FIG. 1. (a) Rotifer scaling to Daphnia. Rotifers that dominated under the ice of Lake Onego: (b) Synchaeta sp., (c) Keratella sp., (d) Kellicottia sp. (pictures from Lake Geneva).

daytime, in between the uppermost limit of the aphotic layer $(3 \mathrm{~m})$ and the maximal vertical migration distance for rotifers reported in literature $(7 \mathrm{~m}$; Karabin and Ejsmont-Karabin 2005). Different swimming speeds (from 0.1 to $1 \mathrm{~mm} / \mathrm{s}$; Stewart and George 1987, Gilbert and Kirk 1988) were tested. In the average model response of the normal DVM model, the simulated ascent was too fast and the descent too early to mimic observed changes in zooplankton abundance under ice (Fig. 2a), suggesting that we were missing pieces of the puzzle.

Interpreting diel changes in rotifer vertical position in terms of DVM tacitly assumes that the underlying mechanisms are similar to those of crustaceans. Yet, laboratory experiments show that these two phyla display very different ecophysiological traits. First, phototaxis is neutral or positive in rotifers, with no evidence for light-triggered shift in phototaxis direction (Clément et al. 1983), defying the essential condition for normal DVM. Instead, rotifers exhibit photokinesis; that is, they swim faster towards the light source as the light intensity increases (Mimouni et al. 1993). Second, physical processes (such as shear or convectively driven turbulent flow) are considered to exert negligible influence on the vertical movements of zooplankton at DVM scales (Pinel-Alloul 1995). This holds true for crustaceans, because they are good swimmers, but the velocity of vertical fluid motion that can be observed at a lake surface (hundreds of micrometers per second; Bouffard and
Wüest 2019) is comparable to the average swimming velocity for rotifers. Therefore, and in contrast to crustaceans, rotifers might have limited abilities to fight against turbulence, and might not fully master their vertical position in the water column. Physical processes also can display a diel rhythmicity, as observed under transparent ice, where the warming, by solar radiation, of near-surface water from the freezing point towards the temperature of maximal density creates daily convection. In Lake Onego on our sampling days, under-ice convection, as measured in situ, started just after sunrise to reach its maximum velocity $(3 \mathrm{~mm} / \mathrm{s}) 3 \mathrm{~h}$ later (Bouffard et al. 2019). The convection was maintained until sunset and finally slowed down and stopped around midnight (Fig. 2b). So, altogether, diel changes in the rotifers vertical position might not be DVM, but instead the product of an active (positive phototaxis) and a passive (transport by daily convection) motion in the water column, an assumption that was tested by a second model.

The second model included both positive phototaxis and photokinesis, along with passive, convectively driven transport (Appendix S1: Section S2). In absence of light, the linear swimming velocity was set at $0.1 \mathrm{~mm} / \mathrm{s}$, increasing to $0.2-1 \mathrm{~mm} / \mathrm{s}$ under daylight. Vertical swimming was considered as the only process driving the vertical position of rotifers if the convection velocity was below a certain threshold (tested for a range of 1.5-3.5 


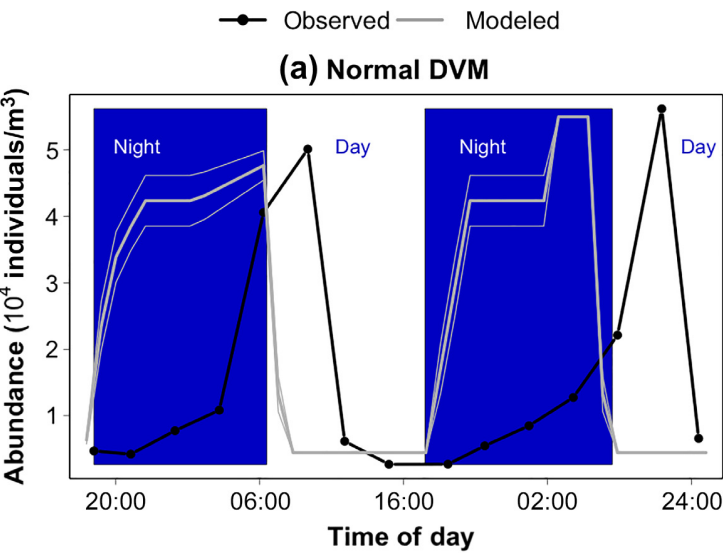

(b) Active swimming-passive transport

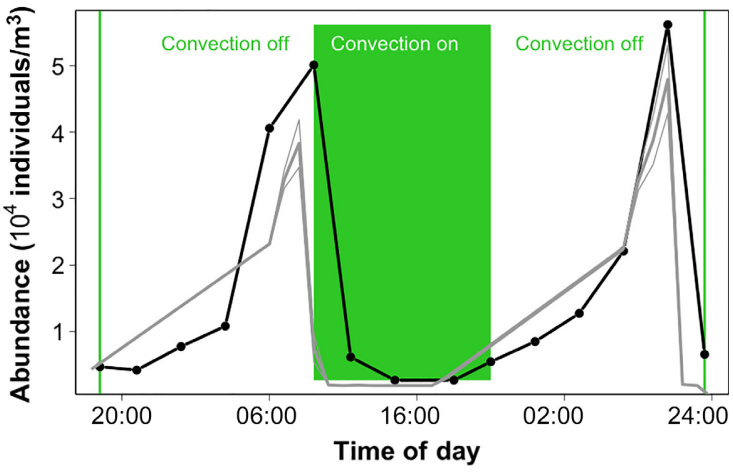

FIG. 2. Observed and modeled abundances (average response $\pm 95 \%$ confidence interval) of total rotifers $0-50 \mathrm{~cm}$ under ice for (a) a normal DVM and (b) a vertical movement depending on active swimming and passive transport by convection.

$\mathrm{mm} / \mathrm{s}, 2 \mathrm{~mm} / \mathrm{s}$ being the maximal linear swimming velocity measured for rotifers; Gilbert and Kirk 1988). Above this threshold, transport by convection was assumed to homogenize the rotifers' abundance within the 12-m thickness of the convective layer. Overall, this second model reproduced the temporal dynamics of zooplankton under ice well (Fig. 2b). Based on the model outputs, a few hours after sunset, convection had slowed down enough to allow efficient swimming by rotifers, but at low speed, because of the absence of daylight. It resulted into a slow increase in the under-ice abundance, until rotifers sped up to the surface at sunrise. Yet, as they attained the uppermost layer, the convection reached velocities strong enough to mix them within the convective layer, until the journey starts over.

Our modeling approach does not pretend to solve the puzzle of rotifer migration, for which additional vertical samplings would be necessary. Instead, it aims for a proof of the concept that the rhythmicity of the physical processes could affect the diel vertical distribution of rotifers. Our active swimming-passive transport model would imply that rotifers constantly chased the surface layer but were washed out soon after they reached it each day, just as Sisyphus forever rolled, to the top of a hill, a boulder that inevitably rolled back down again. The never-ending journey of rotifers might be more widespread than the sole case of Lake Onego. Not only were the convective velocities that we observed under ice moderate as compared to other studies, but also diel convection does not only occur under ice (Bouffard and Wüest 2019). During open waters in many lakes, surface cooling at night induces convection with a reverse rhythmicity as compared to under-ice convection. Would that be enough to turn around the rhythmicity of the vertical motion of rotifers? This could be the perspective from which previous and future field data on rotifers' vertical position could be explored.

\section{ACKNOWLEDGMENTS}

We thank the two anonymous reviewers and the editor, Professor Pastor, for their fruitful comments on this work. This study was supported by the program "Lake Ladoga: Life under Ice" of the Limnology Center of EPFL. The authors would like to thank Roman Zdorovennov, Andrey Mitrokhov, Andrey Georgiev, Alexey Tolstikov, Andrey Balagansky (Northern Water Problems Institute), Michael Plüss (Eawag), and Sebastien Lavanchy (EPFL) for their efforts in data collection, Milla Rautio for her encouragements, and Jasquelin Pena for her comments.

\section{Literature Cited}

Bouffard, D. G., et al. 2019. Under-ice convection dynamics in a boreal lake. Inland Waters 9:142-161.

Bouffard, D., and A. Wüest. 2019. Convection in lakes. Annual Review of Fluid Mechanics 51:189-215.

Clément, P., E. Wurdak, and J. Amsellem. 1983. Behavior and ultrastructure of sensory organs in rotifers. Hydrobiologia 104:89-103.

George, M. G., and H. Fernando. 1970. Diurnal migration in three species of rotifers in Sunfish Lake, Ontario. Limnology and Oceanography 15:218-223.

Gilbert, J. J., and K. L. Kirk. 1988. Escape response of the rotifer Keratella: description, stimulation, fluid dynamics and ecological significance. Limnology and Oceanography $33: 1440-1450$.

Hays, G. C. 2003. A review of the adaptive significance and ecosystem consequences of zooplankton diel vertical migrations. Hydrobiologia 503:163-170.

Karabin, A., and J. Ejsmont-Karabin. 2005. An evidence for vertical migrations of small rotifers - a case of rotifer community in a dystrophic lake. Hydrobiologia 546:381-386.

Lampert W., E. McCauley, and B. F. J. Manly. 2003. Trade-offs in the vertical distribution of zooplankton: ideal free distribution with costs? Proceedings of the Royal Society of London. Series B: Biological Sciences 270:765-773.

Mimouni, P., A. Luciani, and P. Clément. 1993. How females of the rotifer Asplanchna brightwelli swim in darkness and light: an automated tracking study. Hydrobiologia 255:101-108.

Obertegger, U., A. Cieplinski, M. Raatz, and P. Colangeli. 2018. Switching between swimming states in rotifers - case study Keratella cochlearis. Marine and Freshwater Behaviour and Physiology 51:159-173. 
Pearre, S. Jr. 2003. Eat and run? The hunger/satiation hypothesis in vertical migration: history, evidence and consequences. Biological Reviews 78:1-79.

Pinel-Alloul, P. 1995. Spatial heterogeneity as a multiscale characteristic of zooplankton community. Hydrobiologia 300: $17-42$.

Ringelberg, J. 1999. The photobehaviour of Daphnia spp. as a model to explain diel vertical migration in zooplankton. Biological Reviews 74:397-423.
Stewart, L. J., and D. G. George. 1987. Environmental factors influencing the vertical migration of planktonic rotifers in a hypereutrophic tarn. Hydrobiologia 147:203-208.

Additional supporting information may be found in the online version of this article at http://onlinelibrary.wiley.com/doi/10. 1002/ecy.2934/suppinfo 